\title{
CMOS Realization of OTRA Based Electronically Controllable Square Wave Generator Enhancing Linearity with Minimum Total Harmonic Distortion and Power Consumption
}

\author{
Ghanshyam Singh $^{1 *}$, Md.Hameed Pasha ${ }^{2}$, M.Shashidhar ${ }^{3}$, Zulekha Tabassum $^{4}$ \\ ${ }^{* 1,2,4}$ Dept. of Electronics \& Communication Engineering Jayamukhi Institute of Technological Sciences \\ Narsampet Warangal (JNTUH) ,Hyderabad, India
}

${ }^{3}$ Dept. of Electronics \& Communication Engineering Vaagdevi College of EngineeringBollikunta Warangal (JNTUH) ,Hyderabad, India

*Corresponding Author: Ghanshyam Singh, Dept. of Electronics \& Communication Engineering Jayamukhi Institute of Technological Sciences Narsampet Warangal (JNTUH), Hyderabad, India

\begin{abstract}
In this work, we investigate Operational Transresistance Amplifier (OTRA) based square wave generator application. The proposed configuration presents single Operational Transresistance Amplifier (OTRA) with two resistors and one capacitor. The duty cyle of the proposed configuration can be adjusted with the help of varying input voltage and with the help of resistor and capacitor. OTRA as an active building block. The advantage of the proposed configuration electronically tunable and improves its duty cycle with the help of resistor and capacitor. The proposed work describes the circuit operation in SPICE Simulation using $0.18 \mu \mathrm{m}$ CMOS technology. A total harmonic distortion (THD) of $2.10 \%$ with low power consumption is $0.79-0.82 \mathrm{~mW}$ for the frequency ranges $7.92 \mathrm{~Hz}-7.95 \mathrm{~Hz}$ oscillation and total harmonic distortion (THD) of $0.4-0.58 \%$ at the frequency ranges $7.90 \mathrm{KHz}-795 \mathrm{KHz}$ is achieved for excellent linearity.
\end{abstract}

Keywords: Operational Transresistance Amplifier (OTRA), Total Harmonic Distortion (THD), CMOS Technology.

\section{INTRODUCTION}

The proposed square wave generator has vital role in the field of field of communication, Instrumentation and control system, and sound system and also used in radar system. The past few decades the researchers have been presented various active building blocks in the design of electronic circuit in the new areas of analog signal processing and communication.

The most of the active building blocks which have presented less electronically tunable and having more harmonic distortion. These active building blocks namely operational Amplifier (Op-Amp), Operational active building block [11]. The differencing voltage current conveyor (DVCC) [6], VDVTA based sinusoidal oscillator[3],VDTA based sinusoidal oscillator[5], voltage controlled oscillator[7], LC oscillator[8][20], single resistance controlled oscillator[9],OTRA based sinusoidal oscillator[1][2][12] is a recently reported versatile active building block used in the realization of analog signal processing circuits. OTRA is also attractive due to its capability of electronic controllability. The analog circuits using FDCCII based sinusoidal oscillator[10]CDBA based, quadrature oscillator[13][4] ,CFOA based sinusoidal oscillator[14] as active element have been found in the literature, for realization of CMOS Inductor and universal filter [15][16]17][18][19][21]., The DVCC-based sinusoidal oscillators have been proposed in [6] Operational Transresistance Amplifier (OTRA)[1][2][12] is more suitable active building block for electronically tunable in the design of square wave and sinusoidal generators in the area of analog signal and mixed analog signal processing due to these advantages the device gain is independent of stray and junction capacitances which improves the bandwidth.

The proposed square wave generators are very commonly used for music and speech synthesis and it also find applications in other specified fields such as testing of various servo mechanisms, geophysical systems; biological and biomedical fields. An extensive literature review presented its wide application is available on square wave generator in the limited literature. 
CMOS Realization of OTRA Based Electronically Controllable Square Wave Generator Enhancing Linearity with Minimum Total Harmonic Distortion and Power Consumption

In this paper a new CMOS realization of square wave generator employing single OTRA which uses two resistors and one capacitor. [1] [2][12].

\section{Proposed Square Wave Generator Configuration}

The symbolical notation of Operational Transresistance Amplifier (OTRA) is shown in Fig. 1. OTRA is a three terminal device. It comprises of two current inputs $\left(\mathrm{I}_{\mathrm{p}}, \mathrm{I}_{\mathrm{n}}\right)$ and one voltage output $\left(\mathrm{V}_{0}\right)$ and it is characterized by (1). The transresistance gain $\left(R_{m}\right)$ is quite high.

$\left[\begin{array}{l}V_{p} \\ V_{n} \\ V_{z}\end{array}\right]=\left[\begin{array}{ccc}0 & 0 & 0 \\ 0 & 0 & 0 \\ R_{m} & -R_{m} & 0\end{array}\right]\left[\begin{array}{c}I_{p} \\ I_{n} \\ I_{z}\end{array}\right]$

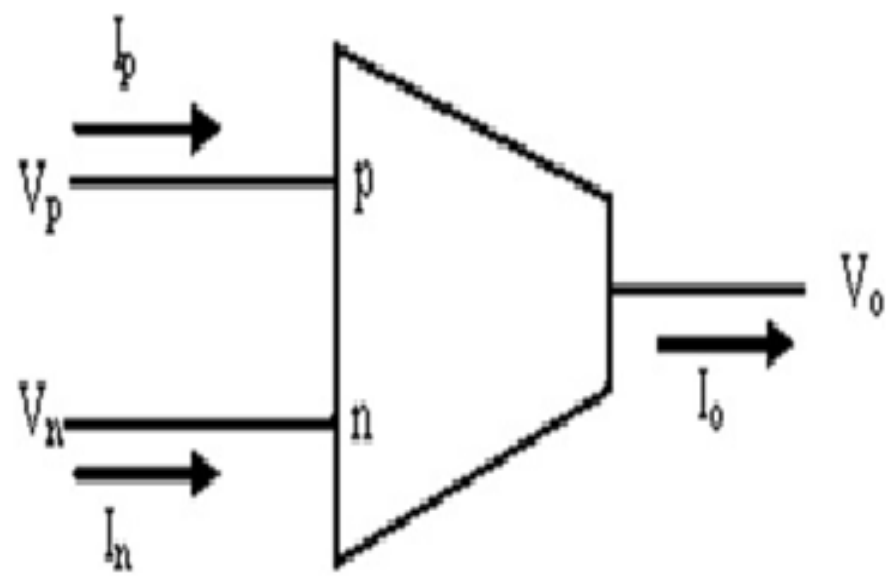

Fig1. Symbolical Notation of OTRA

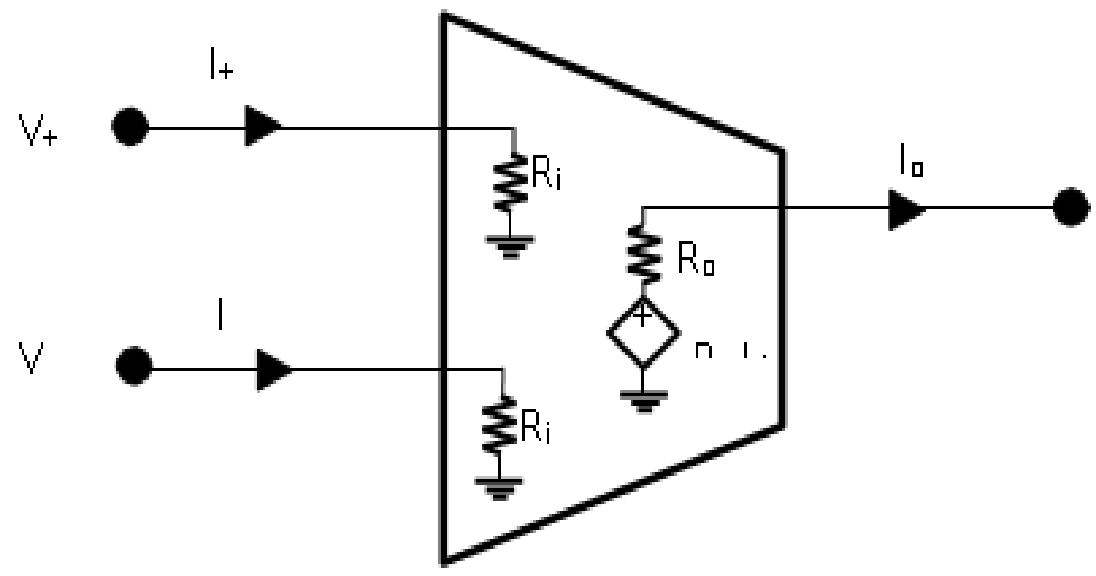

Fig2. Non .Ideal Equivalent of OTRA

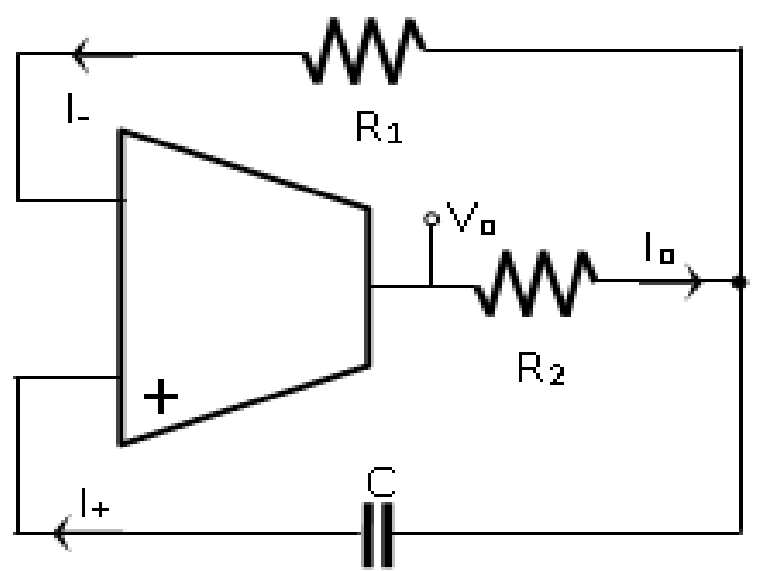

Fig3. (A). Proposed Single OTRA Based Square Wave Generator. 


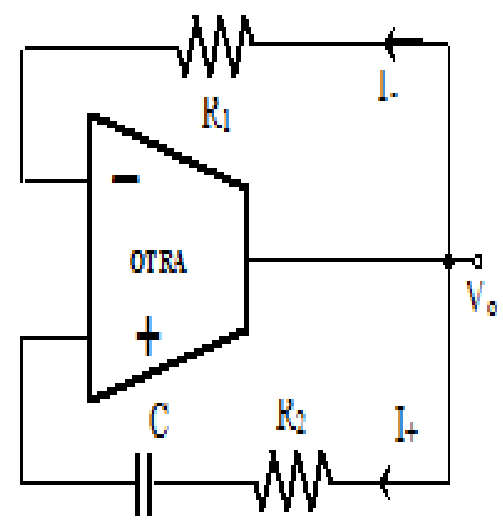

Fig3. (B). Propos Single OTRA Based Square Wave Generator.

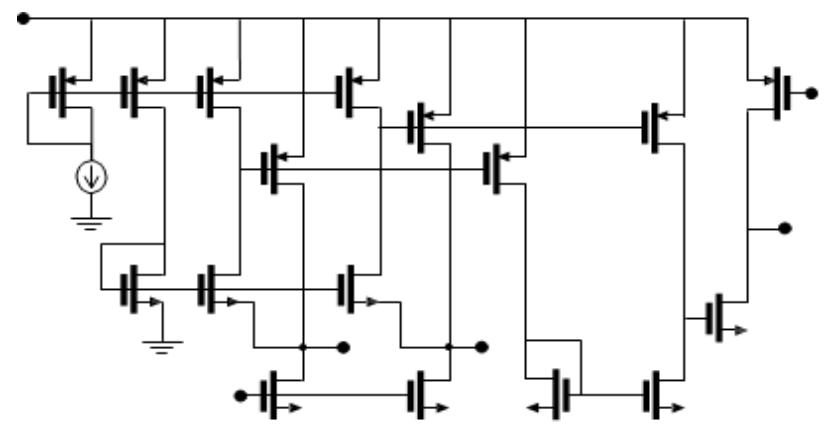

Fig4. CMOS Realization of Single OTRA Based Square Wave Generator

The proposed Operational Transresistance Amplifier (OTRA) based square generator configuration is shown in the fig. $3 \mathrm{a}$ and fig.3b OTRA as the main active building block with two resistors and one capacitor. The square wave generator has been presented. The proposed configuration has been compared with Current Mode and Voltage Mode.

\section{SENSITIVITY ANALYSIS}

The sensitivity of the proposed Operational Transresistance Amplifier (OTRA) based square generator configuration can be defined as the variation in the characteristics due to small changes in the parameters of the proposed Operational Transresistance Amplifier (OTRA) based square generator configuration is shown in the fig.3a and fig.3b OTRA as the main active building block with two resistors and one capacitor.

The sensitivities of the proposed Operational Transresistance Amplifier (OTRA) based square generator configuration is observed with the help of frequency with .respect to C, R2, R1, are less than unity.

Therefore the sensitivities of the proposed Operational Transresistance Amplifier (OTRA) based square generator configurations are very small.

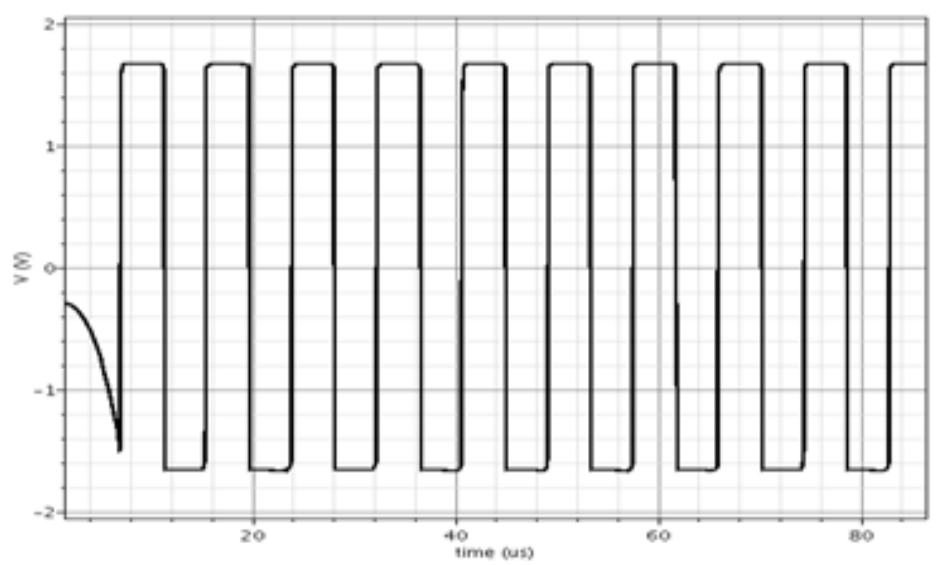

Fig5. Output Wave Form of the Proposed OTRA Based Square Wave Generator 


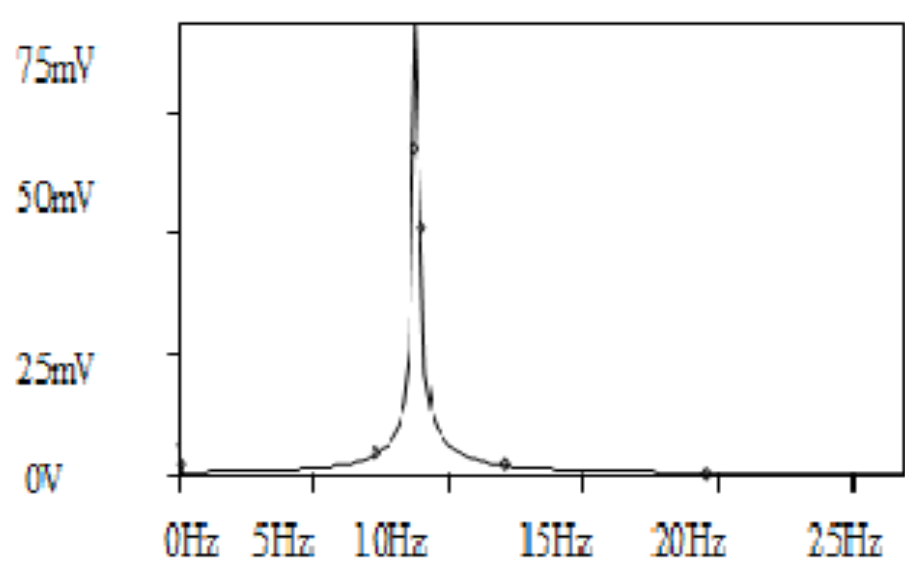

Fig6. Frequency Spectrum of the Proposed OTRA Based Square Wave Generator $F=7.92 \mathrm{~Hz}-8.03 \mathrm{~Hz}$

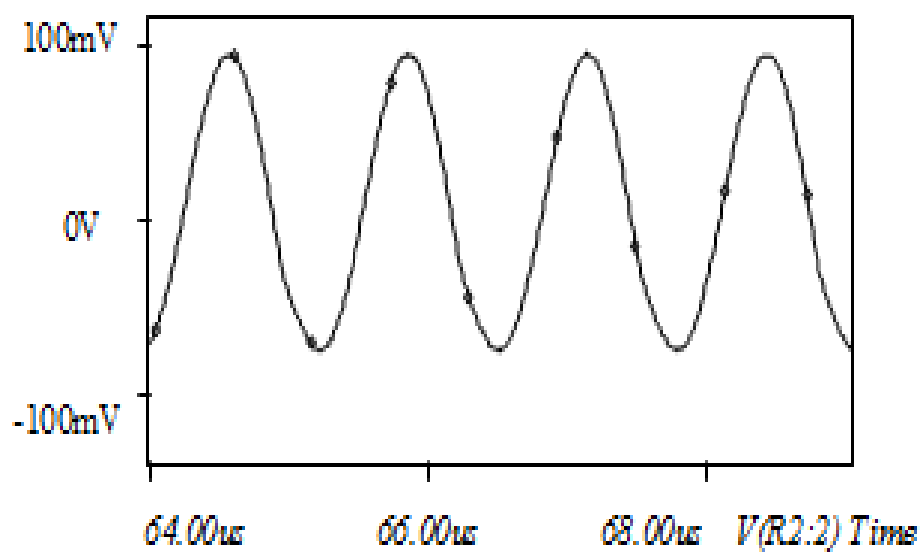

Fig7. Transient Waveform of Proposed OTRA Based Square Wave Generator $F=7.92 \mathrm{~Hz}-8.3 \mathrm{~Hz}$

The linearity of the proposed Operational Transresistance Amplifier (OTRA) based square generator configuration can be improved with the proper selection of C, R2, R1, at low voltage.

\section{Cmos Simulation Results}

The proposed Operational Transresistance Amplifier (OTRA) based square wave configuration is simulated with . $18 \mu \mathrm{m}$ CMOS technology.

The simulation result shows linearity as well as the workability and the functionality of the proposed OTRA based square wave configuration is verified using SPICE simulation. The VSS and VDD used are below $\pm 1.5 \mathrm{~V}$. SPICE simulations are performed for the frequency range $\mathrm{f}=7.90 \mathrm{~Hz}$ to $\mathrm{f}=8.03$ $\mathrm{Hz}$ by the proper selection $\mathrm{R}=1 \mathrm{~K} \Omega$ to $20 \mathrm{~K} \Omega, \mathrm{C}=100 \mathrm{nF}$ to $400 \mathrm{nF}$ and the frequency ranges $790 \mathrm{KHz}-803 \mathrm{KHz}$ by the proper selection of $\mathrm{R} 1=\mathrm{R}_{2}=1 \mathrm{~K} \Omega-3 \mathrm{~K} \Omega, \mathrm{C}=100 \mathrm{nF}$, Time period of CMOS simulated output wave form for the proposed square wave $80 \mu \mathrm{s}-82 \mu \mathrm{s}$ is shown in fig 5 . The $\mathrm{AC}$ analysis and frequency response of the proposed OTRA based square wave configuration is shown in fig 6.The transient response and frequency spectrum of the proposed OTRA based square wave generator are shown in Fig.8 and fig.7 respectively.

The experimental results are verified using SPICE simulation with $.18 \mu \mathrm{m}$ CMOS technology at 790 $\mathrm{KHz}-803 \mathrm{KHz}$ by the proper selection of $\mathrm{R} 1=\mathrm{R}_{2}=1 \mathrm{~K} \Omega-3 \mathrm{~K} \Omega, \mathrm{C}=100 \mathrm{nF}$,

The total harmonic distortion of the proposed OTRA based square wave configuration is $2.09-2.10$ $\%$ with low power consumption is $0.79-.82 \mathrm{~mW}$ at the frequency range between $7.90-8.03 \mathrm{~Hz}$ and total harmonic distortion is $0.4 \%-0.58 \%$ at the frequency ranges $790-803 \mathrm{KHz}$.

\section{CONCLUSION}

In this paper, single Operational Transresistance Amplifier (OTRA) based square wave has been presented. It employs four passive elements namely two resistors and two capacitors. The proposed structure is suitable for medium frequency range. The circuit analyzed for non-ideal effects and 
sensitivity analysis is carried out which shows the sensivities are less than unity. The proposed Operational Transresistance Amplifier (OTRA) based square wave oscillator is verified through SPICE simulations using $0.18 \mu \mathrm{m}$ CMOS process parameters. A total harmonic distortion (THD) of $2.09 \%-2.10 \%$ for the frequency range $7.92 \mathrm{~Hz}-8.03 \mathrm{~Hz}$ oscillation and A total harmonic distortion (THD) $0.4 \%-0.58 \%$ at the frequency range $790 \mathrm{KHz}-8.03 \mathrm{KHz}$ achieved by the proper selection of $\mathrm{R}_{1}=\mathrm{R}_{2}=1 \mathrm{~K} \Omega$ to $3 \mathrm{~K} \Omega, \mathrm{C}=100 \mathrm{nF}$.
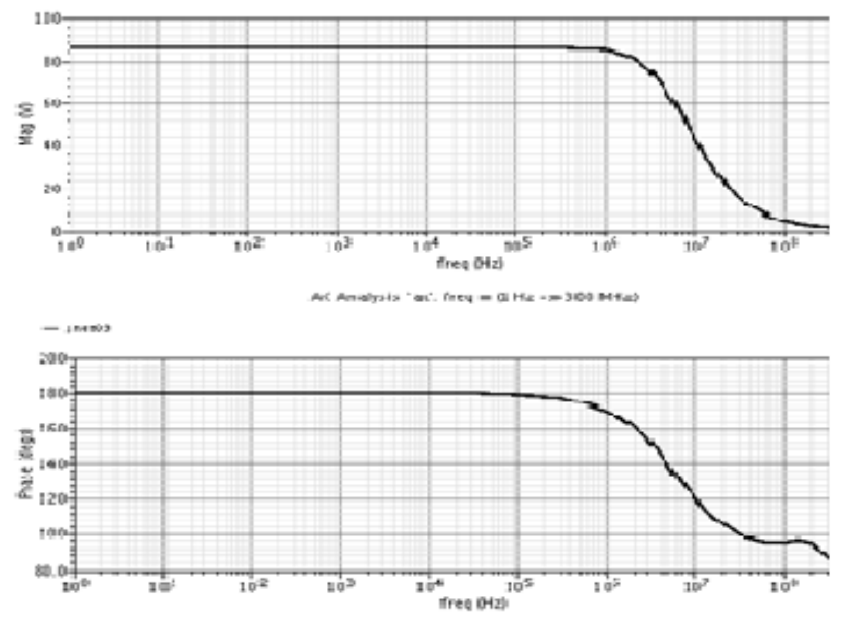

Fig8. AC Analysis and Frequency Response of the Proposed OTRA Based Square Wave Generator

\section{REFERENCES}

[1] R.Senani, A,Singh, A.Gupta, and D.Bhaskar, "Simple Simulated Inductor, Low-Pass/Band-Pass Filter and Sinusoidal Oscillator Using OTRA,” Circuits and Systems, vol.7, pp. 83-99, Mar 2016

[2] R.Senani, D. R. Bhaskar, V. K. Singh, and R. K. Sharma, "Sinusoidal oscillators and waveform generators using modern electronic circuit building blocks," Springer, Switzerland, Nov 2016.

[3] J. Ahmad and D.Prasad, "Novel applications of VDVTA: as current-mode SIMO-type biquad and electronically controllable sinusoidal oscillator," CES, vol. 8, no. 29, pp. 1383 -1391,Oct 2015.

[4] S. Maiti and R. Pal, "Voltage Mode Quadrature Oscillator Employing Single Differential Voltage Current Controlled Conveyor Transconductance Amplifier," IJEEE, vol. 3, no. 5, pp.344-348, Oct 2015.

[5] M.Srivastava, D.Prasad and D. R. Bhaskar, "Voltage mode quadrature oscillator employing single VDTA and grounded passive elements," CES, vol. 7, no. 27, pp. 1501 -1507, Nov 2014.

[6] B. Chaturvedi and S. Maheshwari, "Second Order Mixed Mode Quadrature Oscillator using DVCCs and Grounded Components," International Journal of Computer Applications, vol. 58, no. 2, pp. 42-45, 2012.

[7] Babak soltanian, Tail current shaping to improve phase noise in LC voltage controlled oscillator, IEEE transac-tions on solid state circuits, 2006, Vol. 41, No. 8.

[8] Ming-Juei Wu, Jyh-Neng Yang, and Chen-Yi Lee, A Constant Power Consumption CMOS LC Oscillator Using Improved High-Q Active Inductor with Wide Tuning-Range, IEEE International Midwest Symposium on Circuits and Systems, 2004, pp. 345-350.

[9] U. Cam, "A Novel Single-Resistance-Controlled Sinusoidal Oscillator Employing Single Operational Transresistance Amplifier," Analog Integrated Circuits and Signal Processing, vol. 32, pp. 183-186, Aug 2002.

[10] J. Horng, C. Hou, C. Chang, H. Chou, C. Lin and Y. Wen, "Quadrature Oscillators with Grounded Capacitors and Resistors Using FDCCIIs," ETRI J, vol. 28, no. 4, pp. 486-494, Aug 2006

[11] S. Gupta, R. Sharma, D. Bhaskar and R. Senani, "Sinusoidal oscillators with explicit current output employing current-feedback op-amps," Int. J. Circ. Theor. Appl, vol. 38, no. 2, pp. 131-147, Aug 2008

[12] H.C. Chien, "New realizations of single otra-based sinusoidal oscillators," Active and Passive Electronic Components, vol. 2014, Jan 2014

[13] Lahiri, "Low-frequency quadrature sinusoidal oscillators using current differencing buffered amplifiers," Indian Journal of Pure and Applied Physics, vol. 49, pp. 423-428, Jun 2011.

[14] Lahiri, W. Jaikla and M. Siripruchyanun, "First CFOA-based explicit-current-output quadrature sinusoidal oscillators using grounded capacitors," International Journal of Electronics, vol. 100, no. 2, pp. 259-273, Jun 2012. 
CMOS Realization of OTRA Based Electronically Controllable Square Wave Generator Enhancing Linearity with Minimum Total Harmonic Distortion and Power Consumption

[15] Karsilayan, A. Ilker, and Rolf Schaumann, A high frequency high-Q CMOS active inductor with DC bias control, Circuits and Systems Proceedings, Vol. 1, 2000.

[16] Manjula, J., and S. Malarvizhi, Performance analysis of a low power low noise tunable band pass filter for multiband RF front end, Journal of Semiconductors, vol. 35, No. 3,2014..

[17] H. G. Momen, M. Yazgi,Design of a new low loss fully CMOS tunable floating active inductor, Analog Integrated Circuits and Signal Processing, vol. 89, No. 3, pp. 727-737. 2016.

[18] Mustafa Konal and Firat Kacar, MOS Only Grounded Active Inductor Circuits and Their Filter Applications, Journal of Circuits, Systems and Computers, vol. 26, No. 6, 2017.

[19] Uyanik, H. Ugur, and Nil Tarim, Compact low voltage high-Q CMOS active inductor suitable for RF applica-tions, Analog integrated circuits and signal processing, vol.51, No.3, pp 191-194.2007.

[20] Ming-Juei Wu, Jyh-Neng Yang, and Chen-Yi Lee, A Constant Power Consumption CMOS LC Oscillator Using Improved High-Q Active Inductor with Wide Tuning-Range, IEEE International Midwest Symposium on Circuits and Systems, pp. 345-350,2004.

[21] F. Zhang and P. Kinget, Design of Components and Cir-cuits Underneath Integrated Inductors, IEEE Journal of Solid-State Circuits, pp. 2265-2271.2006

Citation: Ghanshyam Singh, (2019). “CMOS Realization of OTRA Based Electronically Controllable Square Wave Generator Enhancing Linearity with Minimum Total Harmonic Distortion and Power Consumption". International Journal of Innovative Research in Electronics and Communications (IJIREC), 6(1), pp.1-6. DOI: http://dx.doi.org/10.20431/2349-4050.0601001

Copyright: (C) 2018 Authors. This is an open-access article distributed under the terms of the Creat Commons Attribution License, which permits unrestricted use, distribution, and reproduction in any mediu provided the original author and source are credited. 